\title{
Comparison of different tests for the diagnosis of Salmonella typhi in Nineveh Governorate
}

\author{
Bushra Shlla \\ Department of Biology, College of Education for Pure Science, University of Mosul, Mosul, Iraq. \\ E-mail: bdhs56@uomosul.edu.iq
}

(Received May 15, 2021; Accepted June 16, 2021; Available online August 28, 2021)

DOI: 10.33899/edusj.2021.168647, ( ) 2021, College of Education for Pure Science, University of Mosul.

This is an open access article under the CC BY 4.0 license (http://creativecommons.org/licenses/by/4.0/).

\begin{abstract}
Salmonella typhi is one of the most common causes of typhoid fever in Iraq. The aim of this study was to test the synergistic between different tests for the diagnosis of $S$. typhi. It was found, there are ability for preparing local Media which can be used instead of Blood agar for diagnosing typhoid fever by using dates, alfalfa and fish extractors. Both fish and dates extractors were used to prepare a local medium as well as alfalfa and fish. The results showed that dates - fish medium are more efficient than blood agar and alfalfa - fish medium to isolate $S$. typhi. When contrasting culture results with Widal test data of laboratories, it had shown differences in these results because only (57)\% from Widal test was confirmed by culture. When Widal test results were evaluated which is done in different health analysing laboratories in Nineveh Governorate by using Widal test (dilution method) the results showed great differences of results whether result type (positive or negative) or kind of antigens which showed positive results. Leukocyte count was done as a test to enhance the diagnosis of this microbe, it was clear that there is a relation between typhoid fever and decreasing white blood cell count.
\end{abstract}

Keyword: Typhoid fever, Widal test, Culture media

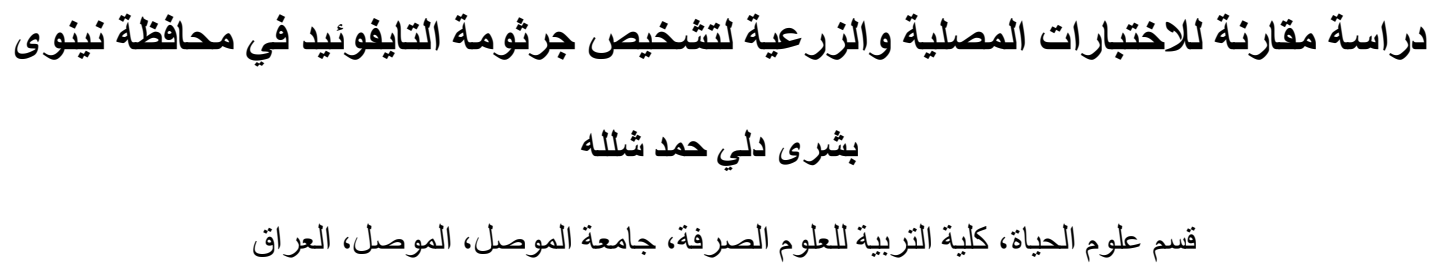

الخلاصة:

اجري هذا البحث بهدف المقارنة بين نتائج زرع عينات دم المرضى المشكوك في إصابتهم بحمى التايفوئيد على كل من وسط أكار الدم والأوساط المحلية المحضرة فضلا عن فحص ويدال Widal test في المختبرات لدراسة التأزر بين الاختبارات لدعم تثخيص حمى لثى التايفوئيد. ووجد ان هنالك إمكانية لإعداد اوساط محلية يمكن استخدامها بدلاً من أكار الدم لتشخيص حمى التايفوئيد باستخدام مستخلص التمر والجت والسمك, حيث تم تحضير وسط التمر والسمك اضافة الى وسط الجت والسمك. وفي دراسة كفاءة الاوساط الزرعية المحلية 
المحضرة في عزل الجرثومة مقارنة بوسط اكار الدم تبين ان وسط التمر والسمك اكثر ملاعمةً من كل وسطي اكار الدم ووسط الجت و السمك لعزل جرثومة S.typhi. و وعند مقارنة نتائج الزرع بنتائج فحص ويدال للمختبرات تبين ان هناللك تباينا في النتائج اذ لم يؤكد الزرع إلا ( 57 ) \% من نتائج ويدال وعند دراسة تقويم نتائج فحص ويدال الذي يجرى في مختلف مختبرات التحليل في محافظة نينوى باستخدام طريقة فحص ويدال بالتخافيف تبين ان هنالك اختلافات كبيرة سواء في نوع النتيجة ( سالبة او موجبة ) او في نوع المستضدات التي اظهرت النتائج الموجبة. كذلك تم إجراء اختبار عد خلايا الدم البيضاء لتعزيز تشخيص هذه الجرثومة، وكان من الواضح أن هناك علاقة بين حمى التايفوئيدية وانخفاض عدد خلايا الدم البيضاء لاى المرضى.

الكلمات المفتاحية : الحمى التايفوئيدية, اختبار ويدال, طريقة الزرع

تعتبر الحمى التايفوئيدية والتي يطلق عليها مصطلح Typhoid fever واحدة من المشاكل الصحية الرئيسة في العالم ومن

ضمنها الدول النامية حيث ينتشر هذه المرض بصورة واسعه مؤدية الى نسب كبيرة من الوفيات في حالة ضعف المعالجة او عدم توفرها اضـافة الى انتثار العزلات والسـلالات المقاومة للمضادات الحيويـة للجرثومة المسببة لحمى التايفوئيد [1] وتشير الاحصـائيات الدولية حتى سنة 2005 الى ان هنالك اكثر من (16) مليون اصـابة سنوية بحمى التايفوئيد على المستوى العالمي تؤدي الى اكثر من ( 600.000 ) حالة وفاة سنوياً تثمل قارة اسيا المرتبة الاولى في معدل الاصـابات بهذا المرض اذ تصل الى نسبة ( 500 - 1000 ) حالة لكل ( 100.000 ) نسمة سنوياً وتقع دولة العراق ضمن هذا المعدل ويعود السبب الى تدني المستوى المعاشي والصحي لمعظم بلدان قارة اسيا الدور الاساس في انتشار حمى التايفوئيد وتفشيه بهذه النسب العالية ، امـا بالنسبة لقارة امريكا الجنوبية وقارة امريكا الوسطى فأن معدل الاصـابة تكون متوسطة نوعاً ما وتصل الى (150 ) حالة لكل ( جنوب وشرق اوربا لتصل الى (4-15 ) حالة لكل ( 100.000 ) نسمة سنوياً وتشمل هذه النسبة كذلك شمال اوربا وامريكا الثمالية واستراليا واليابان حيث يرتفع في هذه الدول المستوى الصـحي والمعاشـي وتكون معظم الاصـابات فيها وافدة اليها من الخـارج عبر المهاجرين والمسافرين او عند تعرض المواد الغذائية فيها للتلوث لسبب او لاخر الثكل( 1-1 ) [3,2] ـ

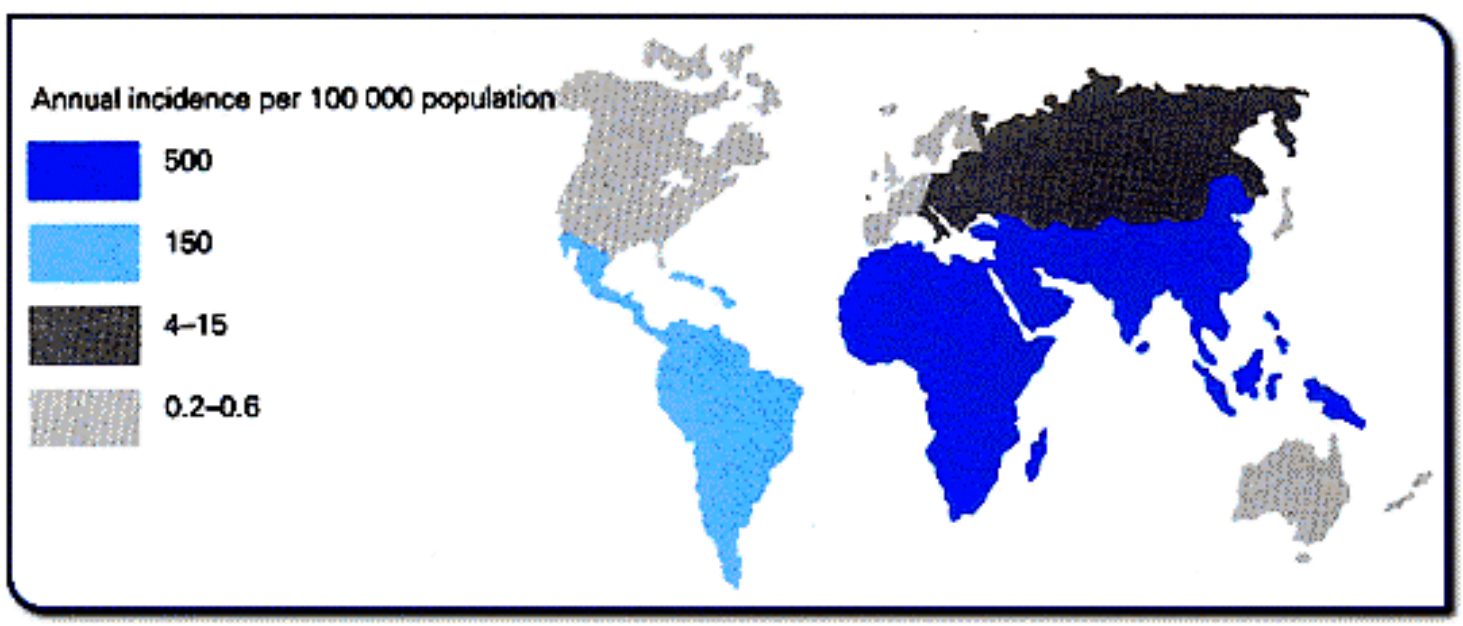

الشكل 1. يوضح التوزيع الجغرافي لمعدلات الاصابة السنوية بحمى التايفوئيد على نطاق العالم ( WHO ، 2004 ) . 
Journal of Education and Science (ISSN 1812-125X), Vol: 30, No: 3, 2021 (187-197)

Special Issue for Proceeding of $3^{\text {rd }}$ National (1 $1^{\text {st }}$ international conference of biology) (ICBSUM 2021) 5, 6 July

College of Education for Pure Science, University of Mosul, Mosul, Iraq.

تعد الـ Typhoid fever التي تسبيها جرثومة التي تسببها Saratyphoid fever الى(1:10) على التوالي [4]. ونتيجة لخطورة المرض فقد سعى العلماء والباحثون بصورة مستمرة الى اكتثاف وتطوير تقنيات جديدة للتشخيص والعلاج لهذة الجرثومة, تستخدم على نحو عام مجموعة طرائق للتشخيص اهمها واكثرها تداولاً الطرق المناعية كطريقة ويدال المناعية المعتمدة على مبدأ التلازن الذي يحصل بين الاجسام المضـادة وكل من المستضد الجسمي(O) والمستضد

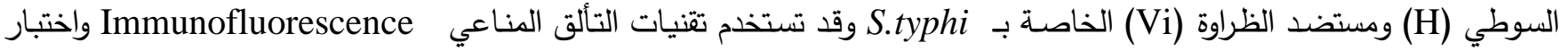
ELISA اضـافة الى طريقـة الزرع وذلك باستخدام عينـات الدم او الخروج او الادرار ونخـاع العظم وغيرهـا وعد خلايـا الدم البيض

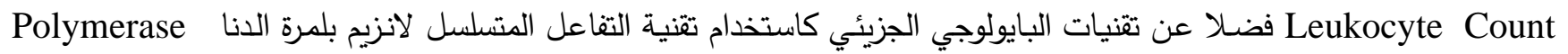
Chain Reaction من دم المرضى المشكوك في إصابتهم بحمى التايفوئيد على كل من وسط أكار الدم والأوساط المحلية المحضرة فضلا عن فحص ويدئ ويدال في المختبرات لدراسة التأزر بين الاختبارات لدعم تشخيص حمى التايفوئيد.

2-المواد وطرائق العمل

Specimens 1-2

جمع ستون عينة دم من المرضى المشكوك بإصابتهج بالحمى التايفوئيدية ممن راجعوا مختبرات مستشفيات (مستشفى الشفاء او الحميات و مستثفى ابن سينا التعليمي و مستثفى الكمالية و مستثفى السلام التعليمي و المستثفى العام) في محافظة نينوى فضلا عن خمسون عينة دم من المختبرات الأهلية التي اختيرت من داخل مركز المحافظة وخارجه وكانت العينات من كلا الجنسين وباعمار مختلفة.

سحب ( 5 ) مل من الدم الوريدي لكل مريض بطريقة معقدة وفي حالة تجارب الزرع فإن العينة أضيفت مباشرة إلى قناني حاوية لوسط Selenite F broth لغرض التنشيط أما في حالة التجارب التي أستخدم فيها مصل الدم فإن العينات كانت تترك للتخثر في درجة حرارة الغرفة ثم وضعت الأنابيب في جهاز الطرد المركزي (3000g) مدة (15) دقيقة لغرض الحصول على المصل الذي فصل بواسطة ماصة دقيقة Micropipette وحفظ في الثلاجة الى حين إجراء الفحص عليه ـ في حين وضعت عينات الدم المسحوبة في قنان خاصة حاوية لمادة مانعة للتخثر نوع ( EDTA ) في حالة تجارب تعداد خلايا الدم البيض [8]. 2-2 2-2 العزلات الجرثومية تم الحصول على السلالة القياسية لجرثومة Syphi م. typ قن قسم علوم الحياة / كلية العلوم / جامعة الموصل ومصدرها معهد السالمونيلا في بغداد وأجريت عليها الاختبارات الكيموحيوية اللازمة المبينة لاحقا لغرض تأكيد التشخيص. Culture media 3-2 الأوساط الزرعية

ضبط الاس الهايدروجيني (متعادل) في الاوساط الزرعيـة وعقدت بجهاز المعقام Autoclave بدرجـة حرارة 121م مدة 15 دقيقة . 
Journal of Education and Science (ISSN 1812-125X), Vol: 30, No: 3, 2021 (187-197)

Special Issue for Proceeding of $3^{\text {rd }}$ National (1 $1^{\text {st }}$ international conference of biology) (ICBSUM 2021) 5, 6 July

College of Education for Pure Science, University of Mosul, Mosul, Iraq.

1-3-2 - 2 1ائوساط الجاهزة

(Oxoid) Nutrient agar الأكار المغذي -

(Oxoid) Nutrient broth المرق المغذي (Oxoid) Selenite F broth وسط مرق السلينايت (Oxoid) Simmons citrate وسط سترات سيمون

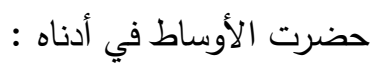

- وسط أكار الدم Blood agar حضر بإضافة (5-10)\% من دم الإنسان إلى وسط أكار الدم الأساس

- (Oxoid) Blood agar base

- وسط ماء الببتون Peptone water

حضـر بإذابـة (20) غم مـن البيتون و (5) غم مـن كلوريــ الصـوديوم (Nacl) في لتر مـن الدـاء الدقطر وضـبط الأس

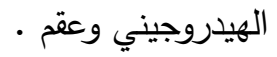

- وسط ماء البيتون والكلوكوز والفوسفيت Glucose phosphate peptone water حضر بإذابة (5) م من البيتون و (5) غم من فوسفات البوتاسيوم ثنائي الهيدروجين (KH2Po4) في لتر من الماء المقطر

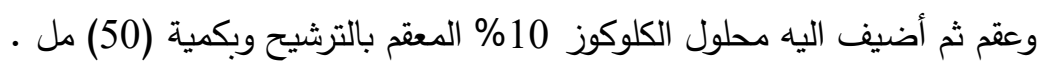

- مسط ماء الببتون والرامينوز والفوسفيت Rhamnose phosphate peptone water

حضر بإذابة (5) غم من الببتون و (5) م من فوسفات البوتاسيوم ثنائي الهيدروجين (KH2Po4) في لتر من الماء المقطر

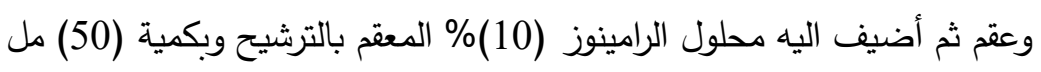
2-2-2 2-2 الأوساط المصنعة

وسط التمر والسمك حُضر هذا الوسط بعد تحضير كل من مستخلص التمر ومستخلص السمك وحسب طريقة [9] المحورة.

ووسط الجت والسمك حُضر هذا الوسط بعد تحضير مستخلص الجت وحسب طريقة [10]

4-2 عزل جرثومة S. typhi وتثخيصها

إن العزلات التي تم الحصول عليها من خلال تجارب زرع عينات دم المرضى وكذلك العزلة القياسية قد شخصت بالإستعانة بالاختبارات المجهرية والزرعية والكيموحيوية IMVIC . I [ [12,11. كما أجريت الإختبارات الآتية : إختبار المثيل الأحمر و إختبار السترات و إختبار الأندول[12] وإختبار فوكس بروسكور [13] 2-2 طريقة زرع الجرثومة على وسط اكار الام والاوساط المحلية لاجل المقارنة . زرعت عينات الدم المأخوذة من المصابين مباشرة بعد سحبها على وسط Selenite F broth لغرض التتشيط اذ حضن الوسط

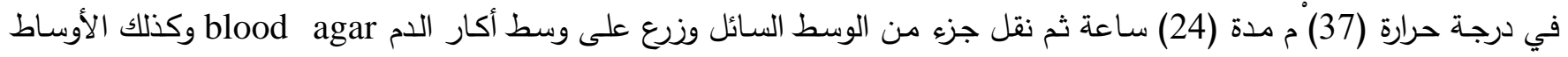


Journal of Education and Science (ISSN 1812-125X), Vol: 30, No: 3, 2021 (187-197)

Special Issue for Proceeding of $3^{\text {rd }}$ National (1 $1^{\text {st }}$ international conference of biology) (ICBSUM 2021) 5, 6 July College of Education for Pure Science, University of Mosul, Mosul, Iraq.

المحلية الدحضرة وحضنت في درجة حرارة (37) م ولوحظ ظهور الدستعمرات النامية التي تم تثخيصها, وأجريت مقارنة بين وسط أكار

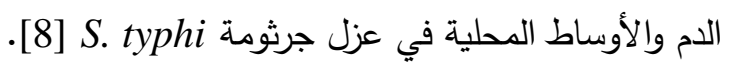

Total leukocyte count 6-6 تجربة عد خلايا الام البيض.

بالاعتماد على [14] ويحسب عدد خلايا الدم البيض كما يأتي : $200 \times$ N = 20 × عد الكريات في 1 ملم = N

النتائج والمناقشة

فصص ويدال المناعي الذي يُجرى في المختبرات لتشخيص مرض التايفوئيد .

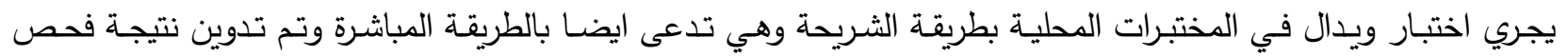
المختبرات المحلية.

\section{مزل الجرثومة وتشفيصها}

تم الاعتماد لعزل الجرثومـة وتثخيصها على عدة إختبارات باستخدام عينات الدم المأخوذة من المرضسى المصـابين بحمى المئ التايفوئيد منذ أسبوع إلى أسبوعين لضمان وجود الجرثومة في هذه العينات قدر الإمكان [15] وأستخدم وسط Selenit F broth لغرض الإن الترات تنشيط النمو لهذة الجرثومة ان وجدت وبعدها تمت الزراعة على الاوساط الصلبة.

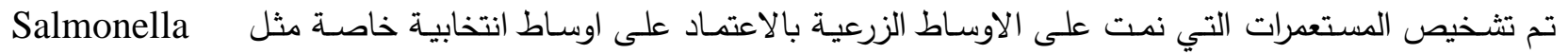
لاستبعاد الأنواع المختلفة من الجراثيم ولاسيما بكتريا القولون Coliformigella Agar (SSA)

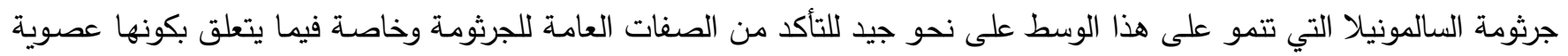

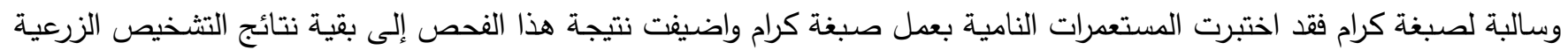
والبايوكيماوية [16,11] ·

وتبين الصورة ( 2 ) نتائج اختبارات IMViC لجميع العزلات وقد اعتمدت النتائج المبينة في هذه الصورة اضافة الى بقية نتائج

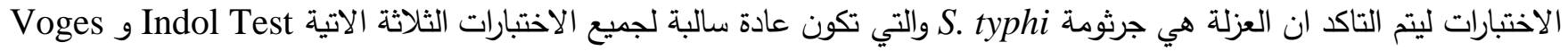
Citrate utilization test و بينما تكون موجبة لـ Methyl Red Test وأنها من بين أنواع السالمونيلا التي لا تكون الغاز عند تخمير سكر الكلوكوز [17] وتم تأكيد تثخيص جرثومة S. typhi بأجراء اختبار تخمير سكر الرامينوز حيث ان هذانه

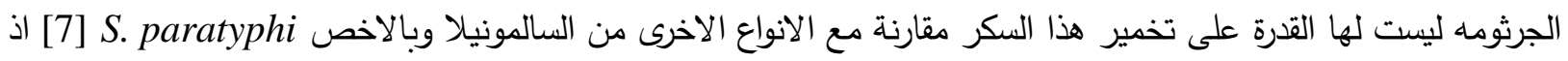




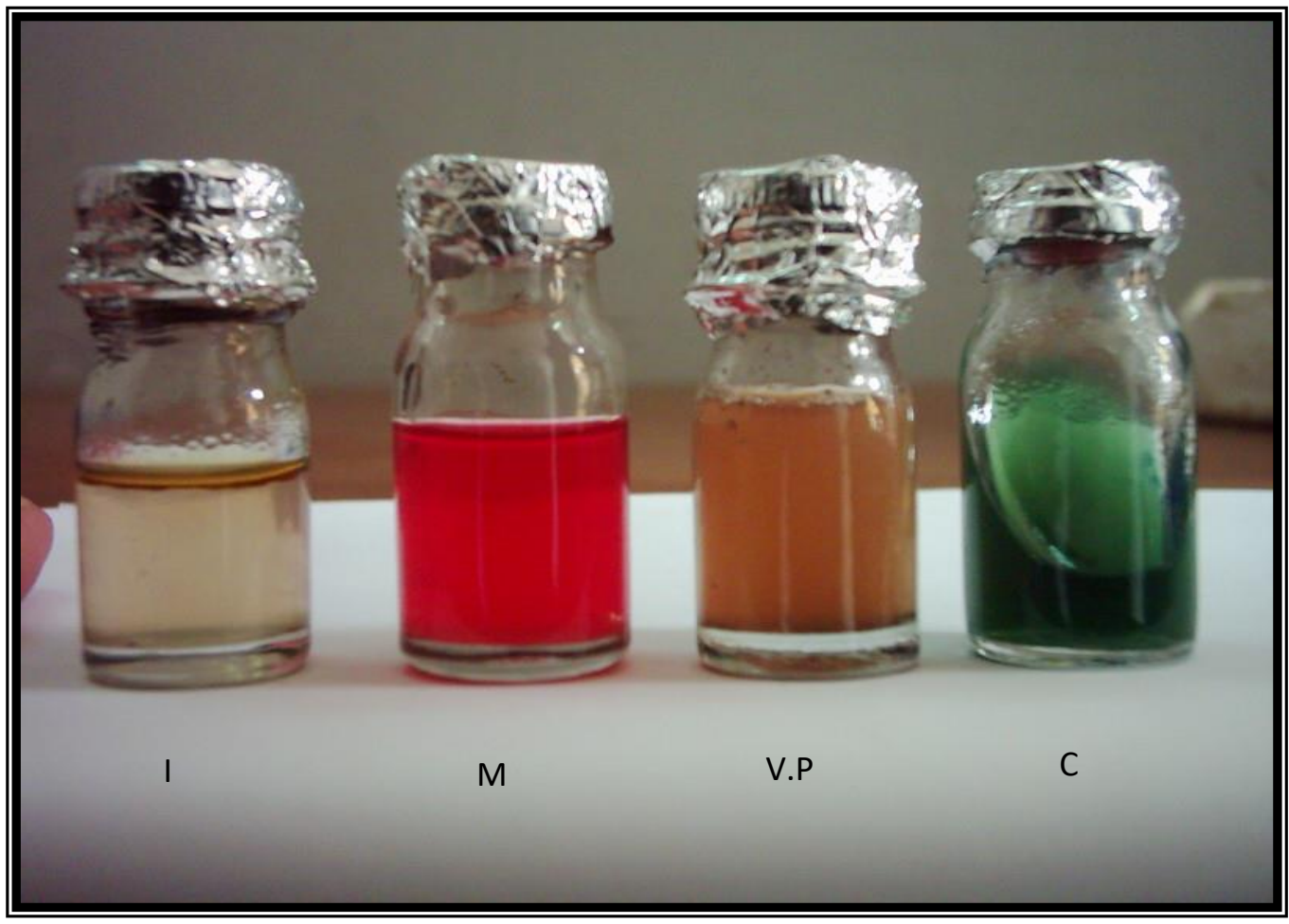

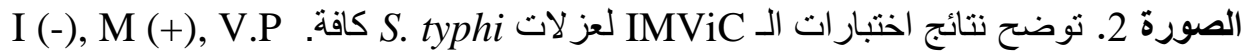

يبين الجدول ( 1 ) نتائج زرع ثلاثين عينة دم اجرت عليها المختبرات مسبقا فحص ويدال والموضحة نتائجها في هذا الجدول كذلك واستخدمت في هذه الدراسة ثلاثة انواع من الاوساط الزرعية هي وسط اكار الدم ووسط التمر والسمك ووسط الجت والسمك بهذف تقييم نتائج اختبار ويدال الذي اجري في المختبرات من جهة فضلاً عن مقارنة كفاءة النمو والعزل لجرثومة S. typhi بين هذه الاوساط من جهة اخرى (1) - من

اظهرت عينات الدم المدروسة نتائج متباينة فيما يتعلق بفحص ويدال اعتماداً على نتائج مستضد منها موجباً ( واحد وعشرون عينة ) واخر سالباً ( تسعة عينات ) وكانت هذه العينات قد اخذت من مصابين اختيروا على انهم يعانون اعراض مرض التايفوئيد ضمن مدة (الاسبوع الاول والثاني كمعدل) لضمان وجود الجرثومة في الدم خلال هذه المدة من الاصـابة [18] فضلا عن عدم اخذ المرضى للمضاد الحيوي.

ظهر نمو جرثومة typhi . من بين العينات المدروسة في ( ثمانية عشر ) عينة مما يؤكد بما لايقبل الثك الاصـابة بهذه الجرثومة ذلك ان اثبات وجودها زرعيا يؤكد هذه الاصـابة [7] ، وتثير النتائج كذلك الى ان هنالك ( اثنتا عشر ) عينة لم يظهر فيها النمو قد يكون السبب في ذلك يعود الى عدم وجود اصابة فعلاً او الى عدم امكان اظهار نمو الجرثومة لان اعدادها قد تكون قليلة جداً في العينة او لعدم دقة معلومات المريض فيما يتعلق بتعاطي المضادات الحيوية خلال المدة التي اخذت فيها العينة وتأثير ذلك في عدم ظعهور النمو اوغيرها من الاسباب[11 
Journal of Education and Science (ISSN 1812-125X), Vol: 30, No: 3, 2021 (187-197)

Special Issue for Proceeding of $3^{\text {rd }}$ National (1 $1^{\text {st }}$ international conference of biology) (ICBSUM 2021) 5, 6 July College of Education for Pure Science, University of Mosul, Mosul, Iraq.

واذا ما اخذنا بالحسبان تقييم نتائج اختبار ويدال لعينات الدم في هذه الدراسة المبينة في الجدول ( 1) من خلال مايقابلها من

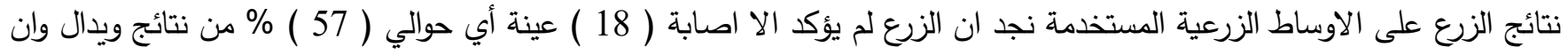

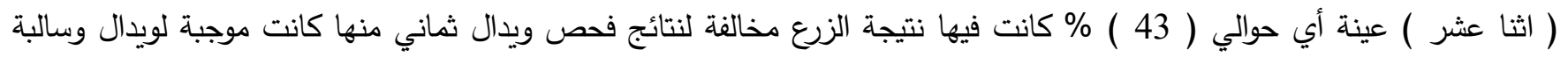
للزرع مما يثكك بوجود اصابة بالتايفوئيد عند هؤلاء المرضى وكانت خمس عينات سالبة لفحص ويدال ولكنها موجبة للزرع مما قد يؤكد وجود اصابة بجرثومة S. typhi عند هؤلاء الاشخاص ـ واذا استند الى نتائج الزرع التي تؤكد معظم المراجع العلمية على اهمية نتائجها

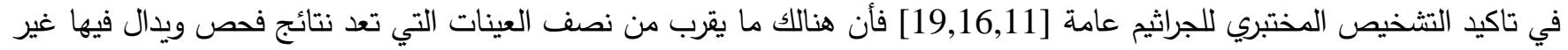
دقيقة ضمن حجم العينات المأخوذة في هذه الدراسة وفي ضوء ذلك نستطيع تصور حجم المشكلة او الخلل في التثخيص المختبري لمرض التايفوئيد اذا ما اخذ بالحسبان العدد الكبير من العينات التي يُجرى عليها اختبار ويدال يومياً في الدختبرات الدختلفة في محافظة نينوى وخاصة في فصلي الربيع والصيف .

الجدول 1. يمثل المقارنة بين نتائج زرع عينات من دم المرضى المشكوك في إصابتهم بحمى التايفوئيد على كل من وسط أكار الدم والأوساط المحلية المحضرة فضلا عن فحص ويدال في المختبرات.

\begin{tabular}{|c|c|c|c|c|}
\hline \multicolumn{3}{|c|}{ ظهور النمو على الأوساط الزرعية المدروسة } & \multirow{2}{*}{ للمنتيد } & \multirow[b]{2}{*}{ 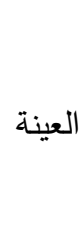 } \\
\hline وسط الجت والسمك & وسط التمر والسمك & وسط أكار الدم & & \\
\hline D & D & D & + & 1 \\
\hline D & D & D & + & 2 \\
\hline $\mathrm{A}(\mathrm{W})$ & $\mathrm{A}(\mathrm{G})$ & $\mathrm{A}(\mathrm{G})$ & + & 3 \\
\hline D & $\mathrm{D}$ & D & + & 4 \\
\hline $\mathrm{A}(\mathrm{G})$ & $\mathrm{A}(\mathrm{G})$ & $\mathrm{A}(\mathrm{G})$ & + & 5 \\
\hline D & $\mathrm{A}(\mathrm{G})$ & $\mathrm{A}(\mathrm{W})$ & + & 6 \\
\hline $\mathrm{A}(\mathrm{G})$ & $\mathrm{A}(\mathrm{G})$ & $\mathrm{A}(\mathrm{G})$ & - & 7 \\
\hline $\mathrm{D}$ & $\mathrm{D}$ & $\mathrm{D}$ & - & 8 \\
\hline $\mathrm{A}(\mathrm{G})$ & $\mathrm{A}(\mathrm{G})$ & $\mathrm{A}(\mathrm{G})$ & + & 9 \\
\hline $\mathrm{A}(\mathrm{W})$ & $\mathrm{A}(\mathrm{G})$ & $\mathrm{A}(\mathrm{W})$ & + & 10 \\
\hline $\mathrm{A}(\mathrm{G})$ & $\mathrm{A}(\mathrm{G})$ & $\mathrm{A}(\mathrm{G})$ & + & 11 \\
\hline D & $\mathrm{A}(\mathrm{W})$ & $\mathrm{A}(\mathrm{W})$ & + & 12 \\
\hline $\mathrm{A}(\mathrm{G})$ & $\mathrm{A}(\mathrm{G})$ & $\mathrm{A}(\mathrm{G})$ & - & 13 \\
\hline $\mathrm{D}$ & $\mathrm{D}$ & D & + & 14 \\
\hline D & $\mathrm{D}$ & D & - & 15 \\
\hline D & D & D & - & 16 \\
\hline $\mathrm{A}(\mathrm{G})$ & $\mathrm{A}(\mathrm{G})$ & $\mathrm{A}(\mathrm{G})$ & - & 17 \\
\hline $\mathrm{D}$ & $\mathrm{D}$ & $\mathrm{D}$ & + & 18 \\
\hline
\end{tabular}


Journal of Education and Science (ISSN 1812-125X), Vol: 30, No: 3, 2021 (187-197)

Special Issue for Proceeding of $3^{\text {rd }}$ National (1 $1^{\text {st }}$ international conference of biology) (ICBSUM 2021) 5, 6 July College of Education for Pure Science, University of Mosul, Mosul, Iraq.

\begin{tabular}{|c|c|c|c|c|}
\hline $\mathrm{A}(\mathrm{G})$ & $\mathrm{A}(\mathrm{G})$ & $\mathrm{A}(\mathrm{G})$ & - & 19 \\
\hline $\mathrm{A}(\mathrm{W})$ & $\mathrm{A}(\mathrm{G})$ & $\mathrm{A}(\mathrm{W})$ & + & 20 \\
\hline $\mathrm{A}(\mathrm{G})$ & $\mathrm{A}(\mathrm{G})$ & $\mathrm{A}(\mathrm{G})$ & + & 21 \\
\hline $\mathrm{D}$ & $\mathrm{D}$ & $\mathrm{D}$ & + & 22 \\
\hline $\mathrm{D}$ & $\mathrm{D}$ & $\mathrm{D}$ & + & 23 \\
\hline $\mathrm{A}(\mathrm{G})$ & $\mathrm{A}(\mathrm{G})$ & $\mathrm{A}(\mathrm{G})$ & + & 24 \\
\hline $\mathrm{A}(\mathrm{W})$ & $\mathrm{A}(\mathrm{W})$ & $\mathrm{A}(\mathrm{W})$ & + & 25 \\
\hline $\mathrm{D}$ & $\mathrm{D}$ & $\mathrm{D}$ & - & 26 \\
\hline $\mathrm{D}$ & $\mathrm{A}(\mathrm{W})$ & $\mathrm{A}(\mathrm{W})$ & + & 27 \\
\hline $\mathrm{A}(\mathrm{G})$ & $\mathrm{A}(\mathrm{G})$ & $\mathrm{A}(\mathrm{G})$ & + & 28 \\
\hline $\mathrm{A}(\mathrm{G})$ & $\mathrm{A}(\mathrm{G})$ & $\mathrm{A}(\mathrm{G})$ & - & 29 \\
\hline $\mathrm{D}$ & $\mathrm{D}$ & $\mathrm{D}$ & + & 30 \\
\hline
\end{tabular}

وبالعودة الى الجدول ( 1 ) ومقارنة كفاءة الاوساط الزرعية الثلاثة المستخدمة في عزل جرثومة S. typhi نجد ان كلاً من وسط

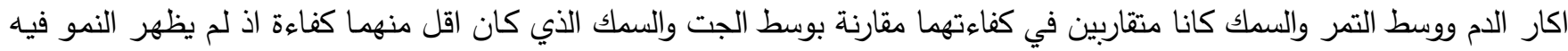

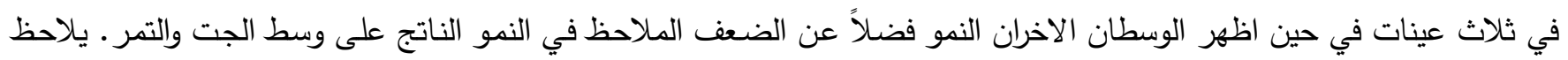
كذلك ان وسط التمر والسمك كان له افضلية نسبية على وسط اكار الدم لا في عدد العينات التي اظهر نموها ولكن في كثافة هذا النمو وكذلك في قابليته الانتقائية على استبعاد الجراثيم الاخرى من خلال احتوائه على مادة Brillant green المهمة بوصفها مادة مثليطة للجراثيم في الاوساط الخاصة بجرثومة Salmonella [12] ، وتنطبق هذه الميزة الاخيرة كذلك على وسط الجت والسمك الذي الظهر

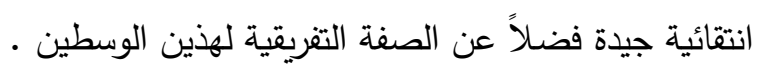

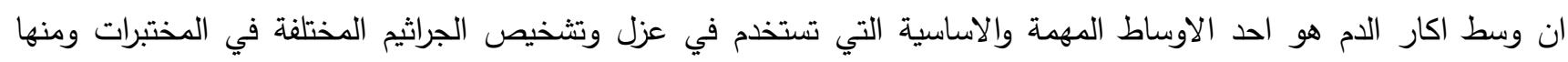

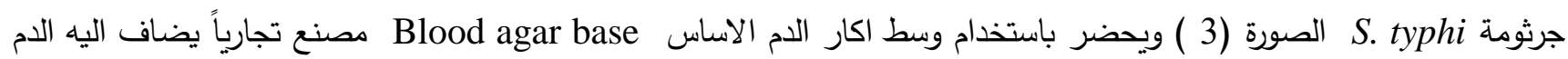
بنسبة محددة وهكذا فهنالك حاجة الى تهيئة هذين الجزئين من اجل تحضير الوسط [7] ماستخدامه في المختبرات الصحية في محافظة نينوى لعزل جرثومة S. typhi محدود جداً لاسباب واعذار متعلقة بطول الددة الزمنية اللازمة لاعطاء النتيجة مقارنة بفحص

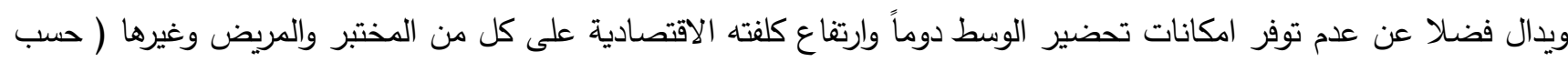
الدراسة الاستبيانية ) هذه الدراسة تهيء نوعين من الاوساط الزرعية المحلية الجيدة في عزل جرثومة S. typhi وتثخيصها وخاصة

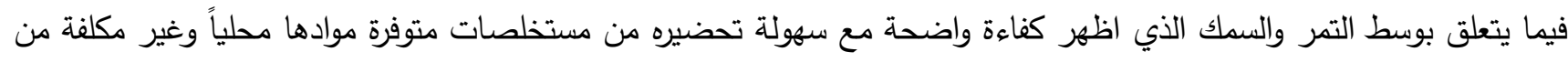

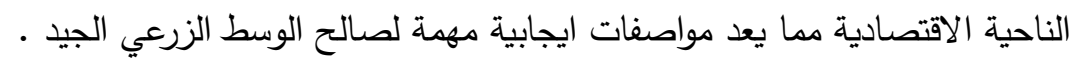




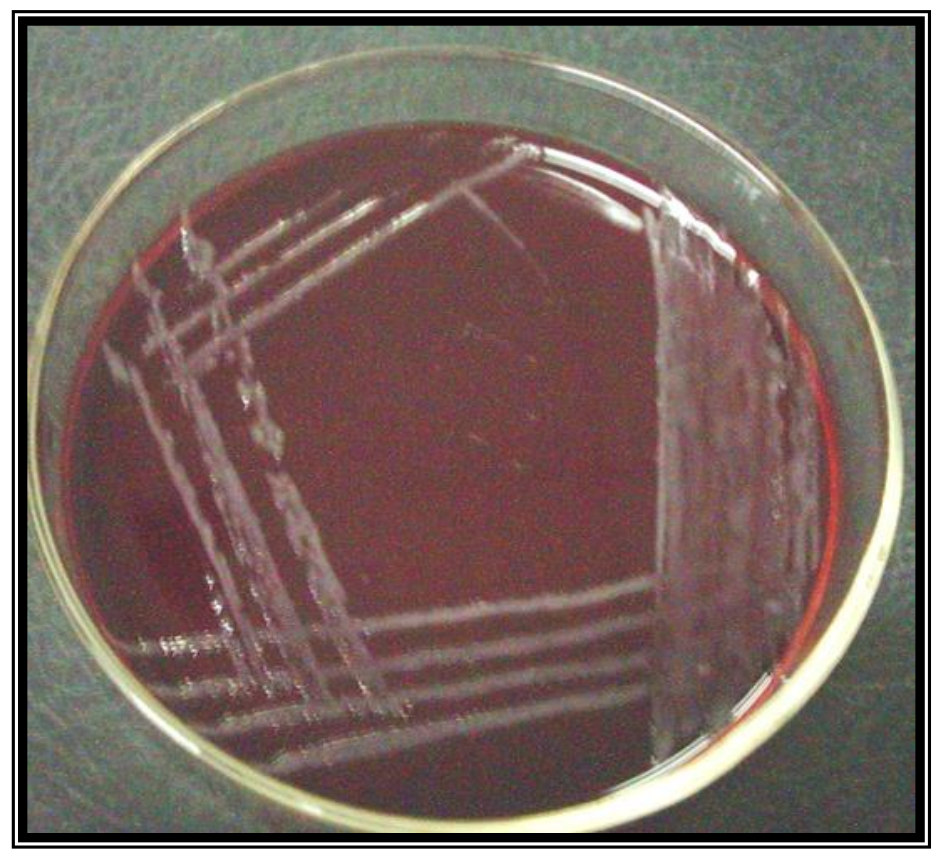

الصورة 3. تبين نمو جرثومة S. typhi على وسط اكار الدم .

\section{اختبارالعدد الكي لخلايا الدم البيض لدعم تشفيص الممى التايفونيدية.}

تم اجراء فحص تعداد خلايا الدم البيض لـ20 عينة دم إجري عليها مسبقا اختبار ويدال باستخدام طريقة التخافيف. وتتضمن العينات ثلاثة عشر عينه موجبة في حين سبعة عينات سالبة لاختبار ويدال لأجل المقارنة. بينت النتائج أن هنالك علاقة بين الإصابة بـ S. typhi وإنخفاض عدد خلايا الدم البيض لدى المرضى, فقد وجد أن احدى عشر عينة موجبة لفحص ويدال إنخفض فيها عدد خلايا الدم البيض بنسبة اقل من خمسة ألاف كرية / سم والذي يعد الحد الفاصل بيّن النسبة الطبيعية وغير الطبيعية لأعداد خلايا الام البيض [21,20] . في حين العينتين الموجبة لاختبار ويدال لم تتخفض فيها اعداد الخلايا عن الحد الطبيعي لسبب ومن جهه اخرى أظهرت جميع العينات السالبة لاختبار ويدال ( أي لاتوجد اصابة ) معدلات طبيعية فيما يتعلق بأعداد خلايا الدم البيض.اكد دراسات عديدة أن الإصابة بحمى التايفوئيد تؤدي إلى إنخفاض في عدد خلايا الدم البيض[23,22,11]

يعتبر اختبار خلايا الدم البيض هو داعم وليس اختبار رئيسي لطرق التشخيص المستخدمه مختبريا لان الاصابة بحى مالطا والملاريا وبعض الفايروسات كذلك يودي الى انخفاض اعداد خلايا الدم [15,11] ويعزو الباحثون هذا الإنخفاض إلى التكسر الذي لئي Neutrophil يحصل لخلايا الدم البيض خلال محاولتها الدفاع والسيطرة على الإصابة ويعتقد أن خلايا الدم البيض من نوع العدلي في حالة حمى التايفوئيد هي التي تعاني من 
الانخفاض من بين الأنواع الأخرى [24]. إن نتائج هذه البحث تدعم التأزر بين هذا الفحص وبقية الفحوصات الاخرى سواء

كان اختبار ويدال او الطرق الزرعية مما يقلل الثكوك المتعلقة بنتائج الفحص علاوة على ذلك فان امكانية أن ترفق نتيجة فحص تعداد خلايا الدم البيض مع بقية الفحوصات كفحص ويدال مثلا مما تعطي مصداقية اكثر له.

تؤكد معظم المراجع العلمية على اهمية نتائج الزرع في تاكيد التشخيص المختبري للجراثيم عامة فأن هنالك ما يقرب من نصف العينات التي تعد نتائج فصص ويدال فيها غير دقيقة ضمن حجم العينات المأخوذة في هذه الدراسة وفي ضوه ذلك نستطيع تصور حجم المشكلة او الخلل في التشخيص المختبري لمرض التايفوئيد اذا ما اخذ بالحسبان العدد الكبير من العينات التي يُجرى عليها اختبار ويدال يومياً في المختبرات المختلفة في محافظة نينوى وخاصة في فصلي الربيع والصيف. يعتبر اختبار خلايا الدم البيض هو داعم وليس اختبار رئيسي لطرق التشخيص المستخدمه مختبريا لان الاصابة بحمى مالطا والملاريا وبعض الفايروسات كذلك يودي الى انخفاض اعداد خلايا الدم. شكر وعرفان اتقدم بالثكر الجزيل لكل من جامعة الموصل و كلية التربية للعلوم الصرفة / قسم علوم الحياة كما اود ان اشكر كلية العلوم / قسم علوم الحياة بأعتبار ها الكلية التي اكملت در استي فئها.

المصادر

[1] Basit, S., Mahmood, I. and Khalid, Q. (1996). Outbreak and management of enteric fever. J. College Phys Surg Pakistan., 6: 28-29.

[2] Molbak, K. and Neimann, J. (2002). Risk Factors for sporadic infection with Salmonella enteritidis,

Denmark, 1997-1999. Am. J. Epidemiol., 156(7): 654-661.

[3] The World Health Report. (2004). Fighting disease Fostering development. WHO, Geneva.

[4] Edwards, C. R. W. and Bouchier, I. A. D. (2000). Typhoid and paratyphoid fever. In: Davidson's principles and practice of medicine $19^{\text {th }}$ ed. Churchill Livingstone. London., : 122-132.

[5] Baron, E. J. and Finegold, S. M. (1990). Bailey and Scott's diagnostic Microbiology. $8^{\text {th }}$ ed., C. V. Mosby company.

[6] Cohen, N. D., Neiberges, H. L., McGruuder, E. D., Witford, H. W., Behle, R. W., Ray, P. M. and Hargis, B. M. (1993). Genus Specific detection of Salmonella using the Polymerase chain reaction. J. Vent Diagn. Invest., 5: 368-371.

[7] Atlas, R. M., Brown, A. E. and Parks, L. C. (1995). Laboratory Manual. Experimential Microbiology, Mosby Comp.

[8] Vandepitte, L., Engbac, K., pito, p. and Heuch, C. C. (1991). Basic Laboratory procedures in Clinical Bacteriology. World Health Organization. Geneva.

[9] Khalaf, S.H. (1975). studies on fish growth media for isloation of pathogenic bacteria . ph. D. Thesis, University of Istanbul. 
[10] Al-Akidi, Muhsin Ayoub Essa. Rafidain Journal of Science., 14:4:73-76 (2002).

[11] Koneman, E. W., Allen, S. D., Janda, W. M., Schreckenberger, P. C. and Winn, W. C. (1997). Coloratlas and textbook of diagnostic microbiology. $5^{\text {th }}$ ed. J. B. Lippincott company, New York.

[12] Cruickshank, R., Dugiud, J. P., Marmion, B. P. and Swain, R. H. A. (1975). Medical Microbiology The practice of Microbiology $12^{\text {th }}$ ed. Churchill living Stone. Edinburgh.

[13] Mcfaddin, J.F. (1985). Biochemical test for identification of medical bacteria, $2^{\text {nd }}$ ed. Waverly Press., Baltimore.

[14] John, D. Bauer, Philip, G. Ackermann and Gelson Toro . ( 1974 ) . Eight Edition. The C. V. Mosby Company.

[15] Collee, J. G., Fraser, A. G., Marmion, b. P. and Simmons, A. (1996). Macie and McCartney practical medical microbiolog. $14^{\text {th }}$ ed. Churchill Livingstone Inc. New York.

[16] Andrews, W. H. (1996). Evaluation of methods for the detection of Salmonella in food. J. Ao Ac international., 79: 4-12.

[17] Bailey, W. R. and Scott, E. G. (1974). Diagnostic microbiology a textbook for the isolation and identification of pathologenic microorganisms. The C. V. Mosby Company. London.

[18] Sood, R. (1994). Medical Laboratory Technolog Methods and Interpretations. $4^{\text {th }}$ ed. Medical publishers CPL, New Delhi. India., : 658-656.

[19] Harly, J. P. and Prescott, L. M. (1996). Microbiology. $3^{\text {rd }}$ ed. WCB McGraw-Hill. U.S.A.

[20] John, D. Bauer, Philip, G. Ackermann and Gelson Toro . ( 1974 ) . Eight Edition. The C. V. Mosby Company.

[21] Falkow, S. and Mekalanos, J. (1990). The Enteric Bacilli and Vibrios in Microbiology. 4th ed. John Willy and sons, IMC, New York. U.S.A.

[22] Freeman, B. A. (1979). The Enteric Bacilli: Salmonella Textbook of Microbiology, Philadelphia: W. B. Saunders Co. Chapter., 19: 518-537.

[23] Edwards, C. R. W. and Bouchier, I. A. D. (2000). Typhoid and paratyphoid fever. In: Davidson's principles and practice of medicine $19^{\text {th }}$ ed. Churchill Livingstone. London., : 122-132.

[24] Stites , D. P., Stobo, J. D., Fudenberg, H. H. and Wells, J. V. (1982). Basic and Clinical Immunology. $4^{\text {th }}$ ed. Card member. U.S.A., : 289. 